\title{
Knowledge Assumptions amongst Doctoral Students: A Case Study at the University of South Africa
}

\author{
RJ (Nico) Botha \\ University of South Africa, Pretoria \\ Email: botharj@unisa.ac.za
}

\section{Doi:10.5901/mjss.2014.v5n20p1068}

\begin{abstract}
This study explores the correlation between a group of South African doctoral students' assumptions about knowledge or epistemological beliefs and their behaviour applicable to research information gathering activities while compiling their research proposals for the doctorate. Six divergent models of epistemological development from the educational psychology (in chronological order) as well as an information search process model formed the conceptual, theoretical framework for the investigation. Ten enrolled doctoral students from the College of Education at the University of South Africa were interviewed about this correlation. The findings provide a rich theoretical foundation for future information-seeking behaviour research among doctoral students and provide insights into the impact of students' epistemological beliefs on their information seeking patterns. The findings furthermore confirm the correlation between core epistemological beliefs and information gathering patterns amongst South African doctoral students and provide substantial justification for using epistemological beliefs in the supervision of doctoral students.
\end{abstract}

Keywords: epistemology; development; knowledge; behavior; doctoral students; South Africa

\section{Introduction}

Most doctoral students encounter and use loads of information during their quest for sources from the literature that are useful and meaningful for the completion of their research proposals and ultimately their theses. This process commences immediately after the students have enrolled for their doctoral degrees as they would be expected to compile a research proposal, according to specified guidelines. In the period of more than 20 years that I spent supervising doctoral students at the University of South Africa, I came to realise that, for the majority of students the writing of theses in most instances becomes a complex, daunting, problematic and most often painful experience. One of the main problems in this regard is that some students, even on doctoral level, simply cannot access or gather the information needed for compiling a research proposal in an effective and rational manner. Some students seem to do a little better in this regard, but information-gathering behaviour among these students seems to be influenced by restraining factors.

One of the restraining factors that play a role in students' information-seeking patterns or lack thereof is that assumptions about the knowledge that each student possesses and how the student constructs knowledge. These, widely referred to as epistemological views or beliefs, have, according to Moser, Mulder and Trout (1998) indeed some implications for their information gathering activities and behaviour in this regard. Researchers who study epistemology are interested in "how individuals come to know, the theories and beliefs they hold about knowing and the manner in which such epistemological beliefs are a part of and an influence on the cognitive processes of thinking and reasoning" (Hofer and Pintrich, 1997, p. 88).

The hypothesis at this point is consistent with what is said above, namely that doctoral students' epistemological beliefs influence the decisions they make as they seek information and evaluate information sources encountered during the information seeking and gathering process.

Although some studies about the epistemological beliefs of undergraduate students such as the Yale study of 1999 (Whitmire, 2003) have been conducted earlier in the United States, no research on this issue have been done locally. In order to address this gap in knowledge, the purpose of this study, based on a qualitative empirical correlation study among ten randomly selected doctoral students from the College of Education at the University of South Africa, was to identify the correlation or association between their respective assumptions or beliefs about knowledge and their information seeking approaches. 


\section{Problem Statement}

When considering the epistemological beliefs of subjects in a study, it is firstly imperative to consider the stages of change according to both time and difficulty as well as the level of cognition at each stage with regard to a person's assumptions about knowledge. Figure 1 below, adopted from Hersey and Blanchard (2001, p. 5), depicts these stages of change.

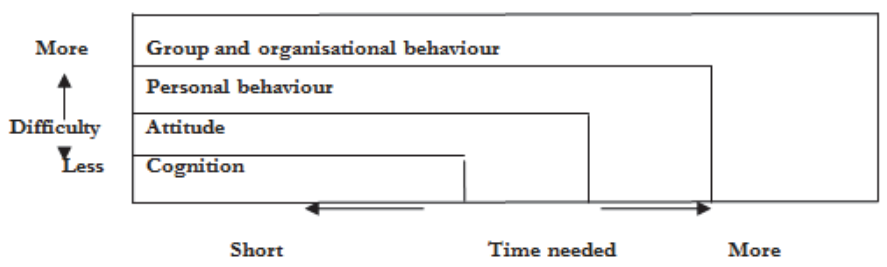

Figure 1. Stages of change according to time and difficulty

According to the figure above, it is clear that the more complex and difficult a person's assumptions about and beliefs in human nature become, the more time he or she will need for the process. For cognition, a short time period is needed for an assumption, while the difficulty level of the process is low, but for a higher level of assumption such as group and organisational behaviour, the individual needs a much longer time period.

An individual's assumptions about human beings, human learning and human nature also include assumptions about knowledge and the nature of various kinds of knowledge. This means that in line with the hypothesis made earlier, there should be a link between these assumptions and the manner in which students gather information for their doctoral studies. This leads to the statement of the problem for this study, which can be phrased as follows: How do a doctoral student's assumptions and beliefs about various kinds of knowledge influence his or her information gathering behaviour? This main research question deals with issues such as doctoral students' epistemological beliefs and the relationship between these beliefs and their information gathering patterns.

Answers to this research question have both theoretical and practical value and can assist supervisors and other academics understand how individuals' epistemological beliefs affect different aspects of information-seeking behaviour.

\section{Literature Review}

Various models or theories of epistemology are discussed in the research literature (http://www.education.com/ reference/article/epistemological-beliefs/). For the purpose of this study, six epistemological development theories from educational psychology provide its theoretical foundation. In addition, the information search process model of Kuhlthau (1993) was used to establish the correlation between epistemological beliefs and information seeking patterns. The six epistemological development models or theories will be briefly discussed in chronological sequence. Each of these theories identify different levels or clusters that can be relate to the information search process model mentioned above in order to establish the correlation between epistemological beliefs and information seeking patterns.

William Perry's (1970) all-male model of intellectual development, developed at Harvard University in the 1970s, will firstly be discussed as it is widely recognised as the first study on university students' intellectual development. All subsequent models of adult epistemological development can trace their origins to this model. Perry (1999) claims (and his claims have since been substantiated by subsequent research) that male college students "journey" through a series of nine "stages" with respect to intellectual development. These stages can be characterised in terms of the male student's attitude, perceptions and views towards knowledge at each stage. Each stage can be grouped into four clusters or categories, namely (http://www.cse.buffalo.edu/rapaport/perry-positions.html-20111219):

- Received knowledge or dualism: All knowledge is known and all problems are solvable. Further, there is certainty that right and wrong answers exist for everything and that the student's task is to learn the right solution and ignore the others.

- Subjective knowledge or multiplicity: There are conflicting answers and therefore students must trust their "inner voice" and not external authorities. Early multiplicity refers to those problems with solutions that we know and those problems with solutions we don't know, while late multiplicity refers to those problems that are 
unsolvable and therefore it does not matter which (if any) solution you choose.

- Procedural knowledge or relativism: All knowledge is contextual and disconnected from any concept of absolute truth. Right and wrong, adequate and inadequate, appropriate and inappropriate, all can exist within a specific context.

- Constructed knowledge or commitment: This is the integration of knowledge learned from others with personal experience and reflection. The student makes a commitment and experiences the implications of the commitment. Students realise that commitment is an ongoing and evolving activity.

What this all means for this study is that students start off as "dualists" by accepting information from the world and reacting to it. They subsequently evolve into "multiplicts" after learning things tacitly and have internal "feelings" about things, but not conscious beliefs that can be explained or justified. They then evolve into "contextual relativists" when they can express their intuitions in language and seek justification for them. They finally get to be "committers" when they establish integration of knowledge learn with their own personal reflections. Each of these four categories will be conceptualised later in conjunction with the information process research model.

The second model to be discussed is that of Belenky, Clinchy, Goldberger and Tarule (1986), which was developed in the 1908s as a response to Perry's all-male Harvard model. In the process, they challenged Perry's elite allmale model as not representative and conducted interviews with women only, culminating in the "women's ways of knowing model" of female epistemological development.

Belenky et al. (1986) used the same approach as Perry (1970) namely an approach of open-ended interviews and interviewed women about their experiences as learners and about how they have changed. The interviewers took a phenomenological approach by using broad questions that allowed the women to describe their experiences in their own words.

This model by Belensky et al. (1986) contains five stages "from which women view reality and draw conclusions about truth, knowledge, and authority", namely (http://www.colorado.edu/ftep/publications /documents/Womens Waysof Knowing.pdf):

- Silence: Total dependence on external authority. This is often a position in which women experience themselves' as mindless and voiceless and subject to the whims of external authority.

- Received knowledge: This is a perspective from which women conceive of themselves as capable of receiving, even reproducing, knowledge from the all-knowing external authorities but not capable of creating knowledge on their own.

- Subjective knowledge: A perspective from which truth and knowledge are conceived by women as personal and private.

- Procedural knowledge: This is a position in which women are invested in learning and applying objective procedures for obtaining and communicating knowledge.

- Constructed knowledge: A position in which women view all knowledge as contextual, experience themselves as creators of knowledge, and value both subjective and objective strategies for knowing.

What this all means for this study is that once a female student assumes the general relativity of knowledge, she begins to construct and reconstruct frames of reference. She then feels responsible for examining, questioning and developing the systems that she will use for constructing knowledge. Each of these five stages will be conceptualised later in the study in conjunction with the information process research model.

The next model or theory to be discussed is that of Schommer. In the late 1980s, Schommer (1990) and others argued for an alternative approach to conceptualising people's epistemological beliefs. According to this model, peoples' epistemological beliefs can be conceptualised according to taxonomy of beliefs or as a system of more or less "independent beliefs". By system, Schommer (1993) means that there is more than one belief to consider, and by more or less independent, she means that a person may be sophisticated in some beliefs of knowledge but not necessarily in others.

Schommer (1993) further argues that epistemologies can be separated into a number of independent beliefs and consequently proposed three beliefs that would be termed epistemological beliefs, namely a belief in how "complex knowledge" is (ranging from complex to simple), a belief in how "certain knowledge" is (ranging from highly certain to highly uncertain) and a belief in the "source of knowledge" (e.g. knowledge coming from authority). These beliefs are more or less independent from one another, for instance, a person may believe in complex but certain knowledge, complex but uncertain knowledge, simple and certain knowledge or simple but uncertain knowledge. With this in mind, Schommer (1993) identifies the following four beliefs as the most important independent beliefs of human knowledge: 
- A belief in simple knowledge. Knowledge is best characterised as isolated facts, and people perceive knowledge as separate and unrelated facts.

- A belief in absolute knowledge. Knowledge is absolute, and people perceive knowledge as a certainty and argue that there is no mistake or error in scientific discoveries.

- A belief in innate knowledge. Learning ability is not changeable and people assume that human ability is not the product of achievement and not subject to improvement.

- A belief in quick learning. Learning is not a gradual process, but when it happens, it happens quickly, or it doesn't happen at all.

Each of these four independent beliefs of Schommer will be conceptualised later in the study in conjunction with the information process research model.

Following the work of Schommer at Harvard, Baxter (1992) consequently developed the "epistemological reflection model" in the 1990s which addressed the gender differences found in the two previous models. She tested both males and females using the same instrument, the Measure of Epistemological Reflection (MER). This instrument is a constructed questionnaire to gain an understanding of participants' perspectives on learning and describes four ways or stages of knowing of students and their development throughout the university experience, namely (Baxter, 1992, p. 30):

- Absolute: knowledge is certain or absolute.

- Transitional: knowledge is partially certain and partially uncertain.

- Independent: knowledge is uncertain; everyone has own beliefs.

- Contextual: knowledge is contextual; judge on basis of evidence in context.

Each of these four stages will be conceptualised later in the study in conjunction with the information process research model.

King and Kitchener (1994) developed the next epistemological model used in this study, namely the "reflective judgement model". This model examines "the ways that people understand the process of knowing and the corresponding ways they justify their beliefs about ill-structured problems" (King \& Kitchener, 1994:13). Their model continues where Perry's (1970) scheme ended, with the final phase of their model being that of reflective thinking. According to Kurfiss (1988), the reflective judgment model is more epistemologically rigorous than Perry's (1970) scheme. King and Kitchener (1994) measure reasoning ability with the Reflective Judgment Interview (RJI). Students were presented with a series of tasks (ill-structured problems) and asked to describe their position on the topic and the reasoning behind this position. The reflective judgment model (King and Kitchener, 1994, p. 17) has seven stages that are divided among three phases, namely:

- Phase 1: Students demonstrate pre-reflective thinking (stages 1 to 3 ) and believe that there are right and wrong answers and that only the authorities know the right answers.

- Phase 2: Students demonstrate quasi-reflective thinking (stages 4 to 5 ) and they begin to question their previously held assumptions and realise that authorities can be wrong or biased. They realise that there can be more than one "correct" answer to a problem.

- Phase 3: Students illustrate reflective thinking (stages 6 to 7) and believe "knowledge must be understood in relationship to the context in which it was generated".

Each of these three phases will be conceptualised later in the study in conjunction with the information process research model.

The last and latest theory of model of the epistemology to be discussed here is that of Hofer (2000) that developed a questionnaire with items that also addresses four very similar, identical epistemological beliefs. Hofer's questionnaire of 2000 was designed so that the questions also referred to a specific field. In other words, in contrast to the questions developed by Schommer, Hofer's questions do not refer to knowledge in general but to knowledge in a specific field such as science and mathematics. The first two epistemological beliefs in Hofer's questionnaire, namely "certainty" and "simplicity", were about the nature of knowledge, while the third and fourth beliefs address the issue of how a person comes to "know" or "learn" something, namely the "source of and justification for knowledge". These four epistemological beliefs of Hofer (2000, p. 391) can be described as follows:

- Certainty. This belief refers to the extent to which the respondent thinks that knowledge is certain as opposed to it being fallible and subject to change.

- Simplicity. This refers to the extent to which the respondent believes that knowledge is structured and organised in simple ways with a single right answer rather than in more complex ways with more than one right answer.

- The source of knowledge. This belief refers to the origin of knowledge: whether it comes from oneself (and 
one's own experiences) or from others (such as the teacher or textbook).

- The justification for knowledge. This belief is closely related to the source of knowledge and is about the kinds of justifications that are offered in support of knowledge. These justifications may be on the basis of personal experience or the authority of experts.

Table 1 below, adapted from Whitmore (2003, p. 131) displays the stages of epistemological development of the six developmental models and exhibits their relationship or correlation with each other. It shows students progress through a series of stages or positions in a hierarchical fashion.

In the beginning of their studies, they often have an absolutist, right-and-wrong view of knowledge. Through their study experiences they begin to perceive knowledge as relative and contingent on the context in which it was created. The first three models focus on how students' epistemological beliefs influence their interpretation of their educational experiences, while the last three models examine how students' epistemological beliefs affect thinking and reasoning ability.

Table 1. The development of epistemological theories

\begin{tabular}{|c|c|c|c|c|c|c|}
\hline Level & $\begin{array}{l}\text { Model 1: Intellectual and } \\
\text { ethical development Perry } \\
\text { (1970) }\end{array}$ & $\begin{array}{c}\text { Model 2: Women's } \\
\text { ways of knowing } \\
\text { Belensky et al. } \\
(1986)\end{array}$ & $\begin{array}{c}\text { Model 3: System of } \\
\text { independent beliefs } \\
\text { Schommer (1990) }\end{array}$ & $\begin{array}{l}\text { Model 4: Epistemological } \\
\text { reflection Baxter (1992) }\end{array}$ & $\begin{array}{c}\text { Model 5: Reflective } \\
\text { judgement } \\
\text { King and Kitchener } \\
\text { (1994) }\end{array}$ & $\begin{array}{c}\text { Model 6: Knowledge in a } \\
\text { specific field/discipline } \\
\text { Hofer (2000) }\end{array}$ \\
\hline Low & Dualism & $\begin{array}{l}\text { Silence Received } \\
\text { knowledge }\end{array}$ & Simple knowledge & Absolute knowing & $\begin{array}{c}\begin{array}{c}\text { Pre-reflective } \\
\text { thinking }\end{array} \\
\end{array}$ & Certainty \\
\hline Medium & $\begin{array}{l}\text { Early multiplicity Late } \\
\text { multiplicity }\end{array}$ & $\begin{array}{l}\text { Subjective } \\
\text { knowledge } \\
\text { Procedural } \\
\text { knowledge }\end{array}$ & Absolute knowledge & $\begin{array}{l}\text { Transitional knowing } \\
\text { Independent knowing }\end{array}$ & $\begin{array}{l}\text { Quasi-reflective } \\
\text { thinking }\end{array}$ & Simplicity \\
\hline High & $\begin{array}{c}\text { Contextual relativism } \\
\text { Commitment }\end{array}$ & $\begin{array}{l}\text { Constructed } \\
\text { knowledge }\end{array}$ & Innate knowledge & Contextual knowing & Reflective thinking & Justification \\
\hline
\end{tabular}

\section{Research methodology}

Kuhlthau's (1993) Information Search Process (ISP) model forms the other dimension of the theoretical foundation of this study. She defines the information search process as "the user's constructive activity of finding meaning from information in order to extend his or her state of knowledge on a particular problem or topic" (Kuhlthau, 1991, p. 361).

The stages of the ISP model are task initiation, topic selection, pre-focus exploration, focus formulation, collection and presentation. In this study the ISP model was used to examine doctoral students' information-seeking behaviour while using the previously mentioned epistemological development models to determine their epistemological beliefs.

From the review of the epistemological development theories discussed above, this study, based on an earlier similar study of Whitmire (2003), hypothesises that participants rated in the lower levels of epistemological development would reject conflicting information while believing that if something was in print or on the web, it must be valid. Participants rated in the medium range of epistemological development would begin to believe that uncertainty exists and that two authors can have differing views on the same subject and that both could be correct. These students would not reject conflicting information. They might believe, however, that knowledge reflects personal beliefs and that the authors are entitled to their own beliefs. Participants rated at the highest levels of epistemological beliefs would evaluate information based on the logical reasoning ability of the authors.

These individuals would begin to think of themselves as capable of creating knowledge and using their own viewpoints to select or reject information sources. They would also consider the context in which the information was formulated and begin to recognise the credibility of particular journals.

Ten postgraduate doctoral students from the University of South Africa (Unisa) were interviewed during 2012 $(n=10)$. The participants included seven male and three female students. The average age of the participants was 43 years. All the students were busy with their doctoral degrees. Participants were purposefully chosen from a number of potential candidates and they represented a sample of convenience (Miles and Huberman, 1994).

An e-mail message requesting the participants to participate in the study was distributed to the 10 postgraduate doctoral students enrolled in the College of Education at Unisa. Interviews were conducted to understand the participants' information-seeking behaviour. An interview guide with a number of embedded questions was designed to assess their epistemological beliefs. The interviews were conducted at Unisa where participants were asked ten questions about their information-gathering behaviour while completing their research proposals. The following pivotal questions focused 
specifically on issues related to doctoral students' epistemological beliefs:

- How did you decide which sources were good enough to use for your proposal?

- What criteria did you use for choosing sources?

- If you came across sources that contradicted each other, how did you treat that?

During the next phase of the research (data interpretation phase), the audiotapes were transcribed. The coding and data analyses consisted of seeking evidence about participants' epistemological beliefs and the influence of their epistemological beliefs on their information gathering patterns. This method of data analysis consists of the normal stages of data analysis using content analysis of research data (Weber, 1990).

None of the six models of epistemological development discussed earlier was used explicitly for data analysis. All of the models, however, were used implicitly to analyse the interview data for evidence of epistemological beliefs. Nevertheless, the six models provided extensive information about the criteria used to assess the epistemological beliefs of the subjects in the study. The study used the three pivotal interview questions (mentioned above) to determine the participants' epistemological beliefs while also considering their responses to the other interview questions involving the role of peers, supervisors and librarians.

For the purpose of this study and for easier data analysis, the different epistemological stages were divided into three sections, namely; low, medium, and high epistemological development levels. The medium level has two dimensions that represent how doctoral students often straddle between low and high epistemological development levels as they develop epistemologically. The participants were placed into categories based on their ability to recognise authoritative information sources and whether or not they believed that knowledge was contextual.

\section{Findings and Discussion}

After conducting content analyses of the interview data, each subject was placed into an epistemological development category. None of the ten participants was placed into the low category. This is consistent with other research that indicated few doctoral students enrolled for the degree with low or without epistemological development. Three of the participants were placed in the high epistemological development category, two in the medium-high category, one in the medium-low category and the remaining four participants in the medium category. Table 2 below indicates the results of the analyses of the interview data.

Table 2: Biographical information with regard to the participants in the study

\begin{tabular}{|c|c|c|c|}
\hline Participant $(\mathbf{n = 1 0})$ & Gender (M/F) & Academic Discipline & Epistemological Level \\
\hline 1 & $\mathrm{M}$ & Education Management & Medium \\
\hline 2 & $\mathrm{~F}$ & Comparative Education & Medium-high \\
\hline 3 & $\mathrm{~F}$ & Didactics & Medium \\
\hline 4 & $\mathrm{M}$ & Education Management & Medium-low \\
\hline 5 & $\mathrm{M}$ & Inclusive Education & Hedium \\
\hline 6 & $\mathrm{M}$ & Education Management & Medium \\
\hline 7 & $\mathrm{M}$ & Socio-education & Medium-high \\
\hline 8 & $\mathrm{~F}$ & Comparative Education & \\
\hline
\end{tabular}

The results of the content analyses confirmed the hypotheses about the expected relationship between epistemological beliefs and information-seeking behaviour. The relationship between these two constructs manifested itself during several stages of the ISP model, particularly during stage 2 up to stage 5 . Epistemological beliefs affected topic selection, the use of supervisors, search techniques, the evaluation of information encountered during the search process as well as the ability to recognise authority. These findings were then related to the different stages of the ISP model and integrated with epistemological development analyses. The following stages emerged:

\subsection{Stage 1: Task initiation (to recognize a need for information)}

The task of writing a research proposal commenced with a requirement that students should read about their respective topics. Epistemological beliefs did not appear to influence this stage. 


\subsection{Stage 2: Topic selection (to identify and select the general topic to be investigated)}

This stage is indeed a very important and complex process for any doctoral student. The participants selected a variety of topics and topic selection was influenced by experience, age, sex and position at the school where each participant is based. Participants were required to complete and submit a short one-paragraph statement indicating the topic they selected before beginning to compile their proposals. This assignment was used to encourage them to make a decision about their topic, but many participants noted that they knew in advance that their stated topic was negotiable and they often changed their topics.

It appeared that on at least one occasion, a student allowed his supervisor to pick a topic for them. This participant was rated as a medium-low epistemological believer. In another instance, a colleague of one of the participants suggested that a medium-high epistemological believer does an analysis of two specific books before finally deciding on a topic for her thesis.

\subsection{Stage 3: Pre-focus exploration (to investigate information on the general topic)}

During this stage, students searched for information on their topic and try to fit newly acquired information into their existing knowledge structures. Kuhlthau (1988) found that her subjects encountered the most difficulty at this stage because they encountered information that was inconsistent or incompatible with their existing knowledge. Often, the information encountered during this stage depended on a student's epistemological beliefs and determined if he/she would continue to pursue the topic. A medium-high epistemological believer stated, "I went through quite a number of different possible topics. I eventually decided that I would do something on school discipline and after reading on the topic, I decided on another topic". Another medium-high epistemological believer noted that "when I didn't find much information about it, I moved on to another topic. I was studying a very new topic that there was little information about it".

Three types of mediators were useful to participants during this stage: supervisors, other students (peers) and subject librarians. Supervisors were commonly cited as referring students to particular information sources, for example, "I talked to my professor a lot and she gave me ideas about other books". Another student said, "I used other students a lot to get recommendations on books". In addition, a medium-high epistemological believer said, "I had a couple of friends who were principals with whom I discussed my studies in general and they all had thoughts as I went along. It was good to use them as a sounding board to hear what my own ideas sounded like". Students also used the bibliographies in the information sources to find other sources or what Ellis (1993) labelled as "citation chaining". One participant said she "looked in the references section and if they mentioned something that seemed to be a key article then I would want to go look that up".

After attending a database-searching class, a medium-high epistemological believer was unable to find many information sources by doing keyword searching. He said it was most helpful to follow citations and flip through journals' tables of contents, what Bates (1989) characterises as "journal run". The most common information-seeking activity was browsing journals. A student who was a medium-high epistemological believer found a pivotal article and describes the process as "I was just randomly looking through a journal and found this article. Actually that was the best way, just to look through every single issue".

A few students mentioned asking subject librarians for assistance. A participant who was a medium-high epistemological believer was referred to a particular librarian by his supervisor. Together, they conducted an exhaustive search of the electronic indexes in his discipline. He was very satisfied with his encounter: "The librarian helped me instead of wasting weeks searching for materials". Another student consulted with a librarian to confirm that he had conducted a thorough search. Most students at this stage search the online public access catalogue to obtain journal articles. Some mentioned that they were able to locate almost all of their information sources in the library. Participants generally were not interested in interlibrary loans and few mentioned using the web at all.

Participants did not appear to know how to conduct very advanced or sophisticated catalogue searches and relied heavily on keyword searching. Searching for journals appeared to be an even more unfamiliar skill. A participant who was a medium-low epistemological believer might have benefited from searching for journals but stated, "I still do not know how to". He continued, "I never had to look up a journal or maybe I should have but just didn't".

Another student said she did not look for journal articles because of laziness and she also did not know how. There were many comments about how frustrating it was to search for journals in electronic indexes and although two students attended bibliographic instruction sessions, this did not lead to successful searches. Participants also complained about how difficult it was to locate journals in what many considered to be the main library, where journals were located in multiple areas of the library. Students who had to find journals in another library expressed satisfaction with this library 
because the journal collection was in one central location in alphabetical order, not call number order. Some students were so frustrated with using electronic indexes to find articles that they physically searched several years of the bound volumes of journals that they identified as important in their field.

\subsection{Stage 4: Focus formulation (to form a focus from the gathered information)}

Kuhlthau (1991, p. 367) described this as a turning point in the process by saying "when feelings of uncertainty diminish and confidence increase". Students were asked to identify a pivotal point in their studies when their research took a sudden turn. A medium-low epistemological believer reached a turning point in her studies during the school holiday break when she had nothing to do other than to read the books that she borrowed from the library. She took notes and realised what her topic was about. She was able to carry out a more focused information search after this point.

Frequently talking about their studies assisted students' to focus more. A student who was a medium-high epistemological believer narrowed her six topics to one topic "based upon the fact that the more I talked about it, the more I formulated what my ideas were". Another participant said that after talking regularly with her supervisor, she began to understand her topic. The best thing for a high epistemological believer was "talking with my professor, because I have so much information to go through".

\subsection{Stage 5: Collection (to gather information related to the focused topic)}

This fifth stage occurs after the pivotal moment when students begin to focus on a specific topic. They used a variety of criteria for evaluating information found at this stage. To assess their epistemological beliefs, participants were asked to describe what they did when they encountered conflicting information and information about how they assessed the authority of their information sources. Encountering information that was inconsistent with their proposals did not seem to trouble most students interviewed. A high epistemological believer said that when she encountered this type of information "it really didn't throw me off or change my topic". A medium-high epistemological believer was not able to determine the validity of her sources and relied on her subject librarian for assistance, "I used the major works". My librarian told me "these are the ones you should really look at".

Another student was comfortable about recognising authoritative journals, "some always pop up, they're huge, famous journals", but then she countered, "I don't, I haven't got enough expertise". This same participant acknowledged that she had to fight the temptation to just disregard conflicting material. Another participant felt more comfortable about assessing the authority of information sources. A high epistemological believer recognised that "there are some journals like I said before that are really good and are known to be really good and if the articles are in there it's probably worthwhile". Another student who was a medium-high epistemological believer said that she would not retrieve an article from an obscure journal because if the article was good it would be in a better journal. A medium-high epistemological believer made a chart of the pros and cons of each argument to help her to process the information. Conflicting information did not bother her; in fact, she said, "I welcomed it".

A high epistemological believer used his experiences living in a foreign country to view the information he encountered. He was concerned that his research subjects were accurately represented in the information that he encountered. He viewed his information sources through his personal experiences by integrating this new knowledge with his existing knowledge. He asked himself, "How does this compare with what I saw? How does this compare with the experiences that I know that people were having?" One student found that "different sources were giving me different evidence either for or against my proposal topic", so she made a chart of pros and cons to decide which side made more sense. She eventually included all of the information sources in her research proposal.

One student judged the validity of an author's argument by how many other people supported the idea, the author's ability to support his or her ideas, and common sense, while another one resolved conflicting views by choosing the authors that everyone else selected. A high epistemological believer felt comfortable considering himself an expert, "I guess the advantage of doing a literary reading of something is that you can just read it and reach your own conclusion". He said he felt competent enough to criticise published authors. A medium-low epistemological believer described her evaluation criteria as follows: "I guess I just went with the consensus, like if I read three authors and two said one thing". She acknowledged that although "we were supposed to incorporate diverging opinions, I'm sure I won't get a good grade because I didn't". She admitted that "I have this bad tendency of just rejecting, you know, ignoring everything that's against my opinion which is one way of doing it but it's not really good because then the people who are arguing with my essay as they're reading it aren't going to find intellectual support". This participant met with her supervisor when she had difficulty selecting a topic for the thesis and was given a topic by the supervisor. 


\subsection{Stage 6: Presentation (to complete the search and to prepare to present the findings)}

Only a few students reached this stage of the ISP model. A high epistemological believer, however, had presented his proposal as a paper at a local conference.

\section{Concluding Remarks}

The study examines the correlation between epistemological beliefs and information-seeking behaviour among a group of doctoral students in a specific setting. This study has both practical and theoretical implications. These findings have practical implications for reference librarians in academic libraries. Depending on a doctoral student's epistemological beliefs, a student will be more or less likely to ask for reference assistance for finding information sources for academic assignments during the exploration stage. Students who are at the higher stages of epistemological development are more likely to seek assistance from reference librarians. These findings also have theoretical implications.

Future research in this field would benefit from the use of other research instruments to measure epistemological beliefs in conjunction with personal interviews to provide triangulation. Longitudinal studies would also be useful because epistemological beliefs are developmental and change during students' exposure to a variety of learning and social activities. In addition, the connection between the various background characteristics, such as gender, socioeconomic status, and disciplinary differences and epistemological beliefs are useful avenues for further exploration. These relationships may affect an individual's information-seeking behaviour and epistemological beliefs.

\section{References}

Bates, M.J. (1989). The design of browsing and berry-picking techniques for the online search interface. Online Review, 13, pp. 407-424.

Baxter, M.B. (1992). Knowing and reasoning in college: Gender-related patterns in undergraduates' intellectual development. San Francisco: Jossey-Bass.

Belenky, M.F., Clinchy, B.M., Goldberger, N.R. \& Tarule, J.M. (1986). Women's ways of knowing: The development of self,voice, and mind. New York: Basic Books.

Ellis, D. (1993). Modelling the information-seeking patterns of academic researchers: a grounded theory approach. Library Quarterly, 63, pp. $469-486$.

Hofer, B.K. \& Pintrich, P.R. (1997). The development of epistemological theories: Beliefs about knowledge and knowing and their relation to learning. Review of Educational Research, 67, pp. 88 - 140.

Hersey, P. \& Blanchard, K.H. (2001). The management of organisational behaviour: leading human resources. Englewood Cliffs, NJ: Prentice Hall.

Hofer, B.K. (2000). Dimensionality and disciplinary differences in personal epistemology. Contemporary Educational Psychology, 25, pp. 378-405. http://www.colorado.edu/ttep/publications/documents/WomensWaysofKnowing.pdf

Accessed on 12 February 2014. http://www.cse.buffalo.edu/rapaport/perry-positions.html-20111219

Accessed on 22 February 2014.http://www.education.com/reference/article/epistemological-beliefs/Accessed on 8 February 2014.

King, P.M. \& Kitchener, K.S. (1994). Developing reflective judgment: Understanding and promoting intellectual growth and critical thinking in adolescents and adults. San Francisco: Jossey-Bass.

Kuhlthau, C.C. (1988). Developing a model of the library search process: Cognitive and affective aspects. Reference Quarterly, 28, pp. $232-242$.

Kuhlthau, C.C. (1991). Inside the search process: Information-seeking from the user's perspective. Journal of the American Society for Information Science, 42, pp. 361 - 371.

Kuhlthau, C.C. (1993). Seeking meaning: A process approach to library and information services. Norwood, NJ: Ablex Publishing.

Kurfiss, J.G. (1988). Critical thinking: Theory, research, practice, and probabilities. Washington, DC: Association for the Study of Higher Education.

Miles, M.B. \& Huberman, A.M. (1994). Qualitative data analysis: An expanded sourcebook (2nd ed.). Thousand Oaks, CA: Sage. Moser, P.K., Mulder, D.H. \& Trout, J.D. (1998). The theory of knowledge: A thematic introduction. New York: Oxford University Press.

Perry, W.G. (1970). Forms of intellectual and ethical development in the college years. New York: Holt, Rinehart, \& Winston.

Perry, W.G. (1999). Forms of intellectual and ethical development in the college years: A scheme. San Francisco: Jossey-Bass.

Schommer, M. (1990). Effects of beliefs about the nature of knowledge on comprehension. Journal of Educational Psychology, 82(3), pp. 498-504.

Schommer, M. (1993). Epistemological development and academic performance among secondary students. Journal of Educational Psychology, 85(3), pp. 406-411.

Weber, R.P. (1990). Basic content analysis (2nd edition). Newbury Park, CA: Sage.

Whitmire, E. (2003). Imposed versus self-generated questions: Implications for reference practice.

In Gross, M 1999. References and Users Services Quarterly, 39, pp. 53-61.

Whitmire, E. (2003). Epistemological beliefs and the information-seeking behavior of under-graduates.

Library \& Information Science Research, 25, pp. 127-142. 